\title{
PROVINCIA DEL TEQUENDAMA - CUNDINAMARCA: PROSPECTIVA DE LA CADENA PRODUCTIVA DE MANGO
}

\author{
Por: Juan Pablo Tribín Rivera ${ }^{1}$
}

\section{RESUMEN}

El propósito del artículo de investigación es exponer el análisis prospectivo de la cadena productiva de mango en la Provincia del Tequendama - Cundinamarca por medio de la metodología de dinámica de sistemas, analizando los antecedentes, el presente y un futuro probable de esta cadena, con el fin de dar a conocer los resultados de la investigación "Mercado Prospectivo del Mango: Comparativo entre el mercado interno y el mercado externo para la Provincia del Tequendama - Cundinamarca".

Las experiencias adquiridas por medio de las visitas de campo, información primaria y secundaria, así como el proceso de modelación y simulación mediante la técnica dinámica de sistemas, permitió desarrollar el escenario prospectivo con mayor potencial para los productores de la Provincia y en consecuencia exponer las opiniones del autor con respecto a lo que deben hacer los participantes para mejorar sus condiciones de ingreso.

Palabras claves: Cadena Productiva, Dinámica de Sistemas, Prospectiva, Diagrama de influencia.

Clasificación JEL: Q110.

1. Profesional en Finanzas y Comercio Exterior, Investigador Universidad Piloto de Colombia. Proyecto Joven Investigador. juan-tribin@unipiloto.edu.co

Fecha de recepción: 20 de febrero de 2014 - Fecha de aprobación definitiva: 10 de junio de 2014 
PROVINCE OF TEQUENDAMA - CUNDINAMARCA: PROSPECTIVE OF THE MANGO PRODUCTIVE CHAIN

\author{
By: Juan Pablo Tribin Rivera
}

\begin{abstract}
The purpose of this research paper is to expose the prospective analysis of mango supply chain in the province of Tequendama - Cundinamarca through the dynamic of systems methodology, analyzing the history, present and probable future of this chain, in order to make known the results of the research proyect "Prospective market of mango: Comparison between the inner and external markets in the province of Tequendama - Cundinamarca".

The experiences gained through field visits, primary and secondary information, and the process of modeling and simulation using dynamic of systems technique, allowed to develop the prospective scenario with the greatest potential for producers of the province and thus expose author's opinions about what participants should do to improve their income.
\end{abstract}

Keywords: Productive Chain, System Dynamic, Prospective, Causal Diagram.

JEL Classification Code: Q110 (Aggregate Supply and Demand Analysis; Prices). 


\section{INTRODUCCIÓN}

El Gobierno Nacional ha reconocido a la agroindustria nacional como uno de los sectores económicos que permitirá el crecimiento y consolidación de la economía colombiana, por ende, mediante la ley 811 de 2003 (Minagricultura, 2003), instituyó las agrocadenas a nivel nacional y la incluye en el Plan Nacional de Desarrollo 2010-2014 (DNP, 2010), dando continuidad a las políticas generales de los últimos gobiernos.

La cadena productiva de mango es una de las que presenta mayor potencial exportable a nivel mundial. Según datos suministrados por la FAO (Food and Agriculture Organization of the United Nations, 2013), las exportaciones mundiales de mangos, mangostanes y guabas han presentado un incremento del 33\% en la serie de tiempo 2005-2009, pasando de una producción de 942.190 toneladas métricas a 1.255.712 toneladas métricas lo que enmarca una demanda creciente para este producto.

Según el Acuerdo de Competitividad de Productos Hortofrutícolas Promisorios Exportables de Colombia (Asohofrucol, 2005-1), la cadena productiva de mango es considerada como una cadena promisoria competitiva, lo que indica que tiene un gran potencial exportable en el mercado internacional. Según la FAO (2013), para el año 2010 la producción de mangos, mangostanes y guabas en Colombia fue de 243.375 toneladas métricas y según Agronet (2012), la producción de mango llegó a las 257.449 toneladas en el año 2012, en ambos casos la producción de mango ha sido creciente en los últimos años.

En Colombia, el departamento de Cundinamarca dadas sus condiciones climáticas, pluviosidad y diversidad de pisos térmicos, presenta un entorno propicio para la producción de mango. Según Cardozo (2011: 43), el mango ostenta una posición favorable entre los productos exportables del departamento, dadas las condiciones de demanda mundial, la regularidad del cultivo y los altos niveles de producción con respecto a otros productos agrícolas. Cundinamarca pasó de producir 24.836 toneladas de mango en el año 2001, a producir 90.154 toneladas para el año 2012, la más alta a nivel nacional (Agronet, 2012) con una representatividad del 35.2\% para este último año. Adicionalmente la producción de mango representa el 26.1\% de la producción de frutales del Departamento, lo que la ubica como una de las agro cadenas frutales más importantes.

En Cundinamarca, la provincia del Tequendama, que está compuesta por diez (10) municipios: Tena, Anapoima, Anolaima, Apulo, Cachipay, El Colegio, Quipilé, San Antonio, Viotá y La Mesa, presenta una de las mayores producciones del Departamento junto con la Provincia del Alto Magdalena, con 55.642 toneladas para el año 2009 y uno de los mejores indicadores de utilización de tierras del Departamento (Universidad del Rosario, 2011-26). Adicionalmente, esta provincia representa el $60.2 \%$ de la oferta de mango que llega a la Central de Abastos de Bogotá (Corabastos), lo que muestra la importancia de esta provincia en el suministro de este producto en la capital del país. 
Pese a que la cadena productiva de mango presenta unas condiciones favorables de entorno, cultivo, demanda y producción, las exportaciones de mango han sido decrecientes en los últimos años. Pasando de exportar 12.712 toneladas en 2001 a 354 toneladas en 2011 (Agronet, 2012).

Las premisas anteriormente expuestas muestran un escenario contradictorio en el cual el mango presenta un entorno favorable para su cultivo, y niveles cada vez más altos de producción, sin embargo sus exportaciones son decrecientes pese al entorno favorable. Tal situación contradictoria motiva el proyecto de investigación, con el cual se analizarán las variables que generen dicho escenario. Varios interrogantes se presentaron de la situación anteriormente expuesta:

- ¿Cuál es el mercado prospectivo con mayores potencialidades para la cadena productiva de mango en la Provincia del Tequendama - Cundinamarca, el nacional o el internacional?

- ¿Cuáles condiciones en la cadena productiva de mango en la Provincia del Tequendama - Cundinamarca generan la relación contradictoria entre sus cada vez mayores niveles de producción y cada vez sus menores niveles de exportación?

- ¿Qué problemas existen en la cadena productiva de mango en la Provincia del Tequendama - Cundinamarca en los procesos de abastecimiento, comercialización y mercadeo en el mercado nacional e internacional?

- ¿Es posible formular un modelo de simulación que articule la cadena productiva de mango en la Provincia del Tequendama - Cundinamarca y la explique bajo escenarios?

Con base en estos interrogantes se siguió la metodología de investigación propuesta por Guadarrama (2009), y se plantearon las hipótesis del proyecto de investigación:

- El mercado prospectivo con mayores oportunidades para los productores de mango en la Provincia del Tequendama - Cundinamarca es el externo, dadas las condiciones de precio que en éste se maneja.

- Las condiciones contradictorias entre producción y exportaciones en la cadena productiva de mango en la Provincia del Tequendama - Cundinamarca son derivadas a las condiciones de competitividad de ésta.

- Los problemas en la cadena productiva de mango en la Provincia del Tequendama derivan de los eslabones productor e intermediario. Adicionalmente los costos logísticos en Colombia no permiten un adecuado desarrollo de la competitividad en la cadena productiva de mango en la Provincia del Tequendama - Cundinamarca.

- Se puede generar un modelo de simulación que pronostique la cadena productiva de mango en la Provincia del Tequendama - Cundinamarca. 
Para poder validar o falsear dichas incógnitas, se generaron los objetivos general y específicos del proyecto de investigación:

\section{Objetivo General:}

- Analizar las potencialidades de la cadena productiva de mango en el mercado interno frente al mercado externo, para la Provincia del Tequendama - Cundinamarca, a través del diseño de un modelo de simulación matemático bajo dinámica de sistemas.

\section{Objetivos Específicos:}

- Diagnosticar el estado de la cadena productiva de mango en la Provincia del Tequendama - Cundinamarca en cada uno de los procesos de abastecimiento, comercialización y mercadeo nacional e internacional.

- Analizar las problemáticas de la cadena productiva de mango en la Provincia del Tequendama - Cundinamarca en cada proceso de abastecimiento, comercialización y mercadeo nacional e internacional.

- Identificar el escenario prospectivo con mayor potencial entre el mercado interno, externo o mixto, para la cadena productiva de mango en la Provincia del Tequendama - Cundinamarca por medio de un modelo de simulación matemático bajo dinámica de sistemas.

El propósito del estudio era realizar un análisis prospectivo de la cadena productiva de mango en la Provincia del Tequendama - Cundinamarca con el fin de determinar el mercado más conveniente para los cultivadores de la provincia, sea este el mercado nacional o el internacional, y para ello era necesario un instrumento que permitiría generar una representación abstracta de la realidad, con la cual se podría analizar la cadena productiva de mango partiendo de las experiencias de campo y con la que se podrían simular las variables más relevantes de dicha cadena productiva. Por lo tanto se identificó la dinámica de sistemas como la herramienta idónea que permitiera realizar el análisis prospectivo de la cadena productiva de mango.

A continuación se expone el análisis realizado a la cadena productiva de mango en la provincia del Tequendama - Cundinamarca, partiendo de los antecedentes y el presente de la cadena, lo cual permitió identificar la composición, las variables y el estado de esta.

Posteriormente se explica la integración entre la prospectiva y la dinámica de sistemas, lo que permite modelar la cadena productiva y comprenderla por unos escenarios probables específicos, los cuales fueron seleccionados por el investigador.

Para finalizar se exponen las conclusiones y las recomendaciones a los productores de la cadena productiva dando respuesta a las hipótesis planteadas en la estructura metodológica del proyecto de investigación. 


\section{ANTECEDENTES DE LA CADENA PRODUCTIVA DE MANGO EN LA PROVINCIA DEL TEQUENDAMA - CUNDINAMARCA}

Los antecedentes de la cadena productiva de mango en la Provincia del Tequendama - Cundinamarca se pudieron identificar por medio de las fuentes primarias y secundarias al momento de realizar el estado del arte del proyecto de investigación. Esta etapa previa a la construcción del marco teórico permitió identificar el comportamiento de diversas variables productivas en la cadena.

Pese a que con anterioridad se citó los niveles de producción en el entorno nacional y regional de la cadena productiva, a continuación se retoman para reconocer las tendencias de la cadena productiva.

La producción de mango en Colombia ha sido creciente en la serie de tiempo 1992 - 2012 (Figura 1), para el año 2012 la producción nacional alcanzó las 257.449 Toneladas, cosechadas de 21.690 hectáreas de cultivo. El rendimiento (Ton/Has) se situó en un cociente igual a 11,9.

Figura 1. Área Cosechada y Producción de Mango en Colombia (1992-2012).

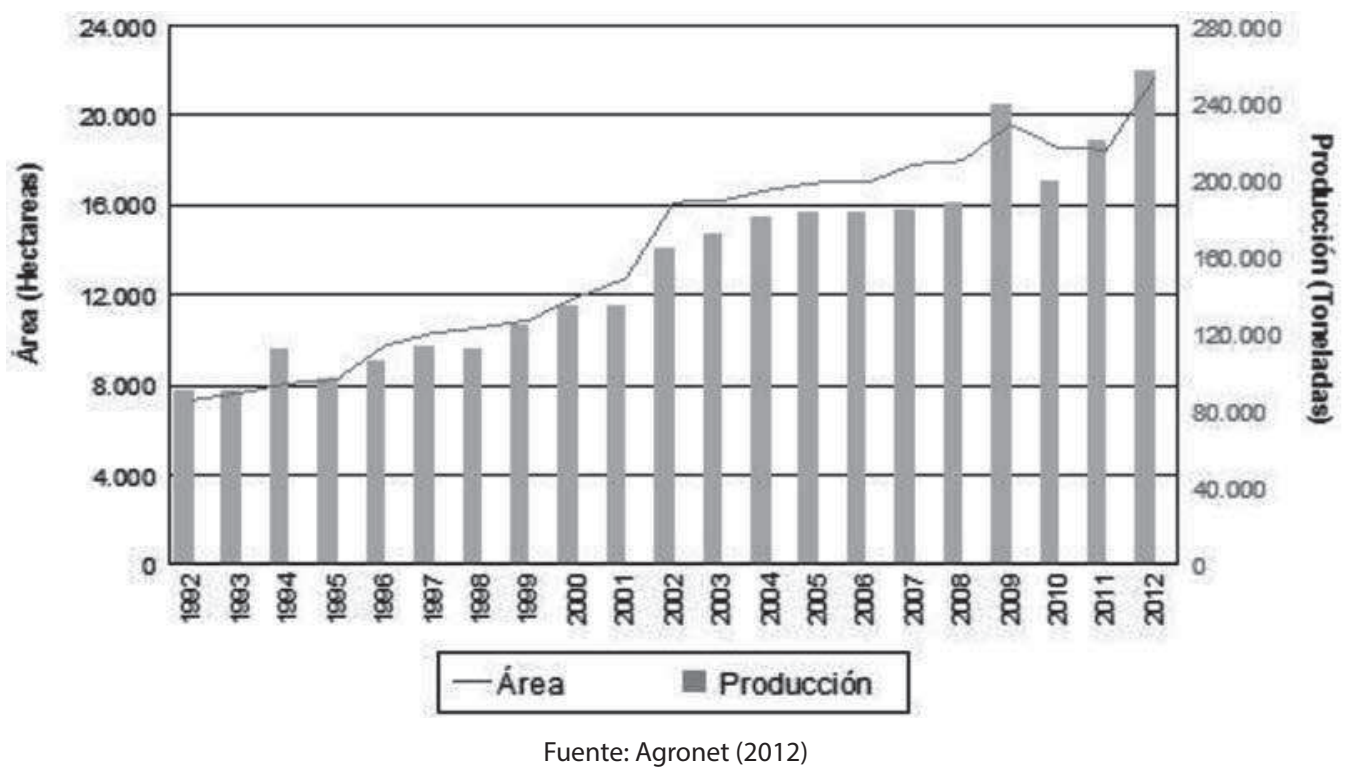

Para el año 2012 los departamentos que ostentan los mayores niveles de producción, en orden de representatividad, son Cundinamarca, Tolima y Magdalena.

Cundinamarca siendo el departamento de mayor aporte de la cadena productiva nacional (35,02\% de la producción nacional), sigue la tendencia nacional en cuanto a producción y área cosechada para la serie de tiempo 1992-2012 (Figura 2). En el último año de esta serie Cundinamarca produjo 90.154 toneladas, cosechadas de 8.399 hectáreas. El cociente de rendimiento (Ton/Has) es igual a 10,7. 
Figura 2. Área Cosechada y Producción de Mango en Cundinamarca (1992-2012)

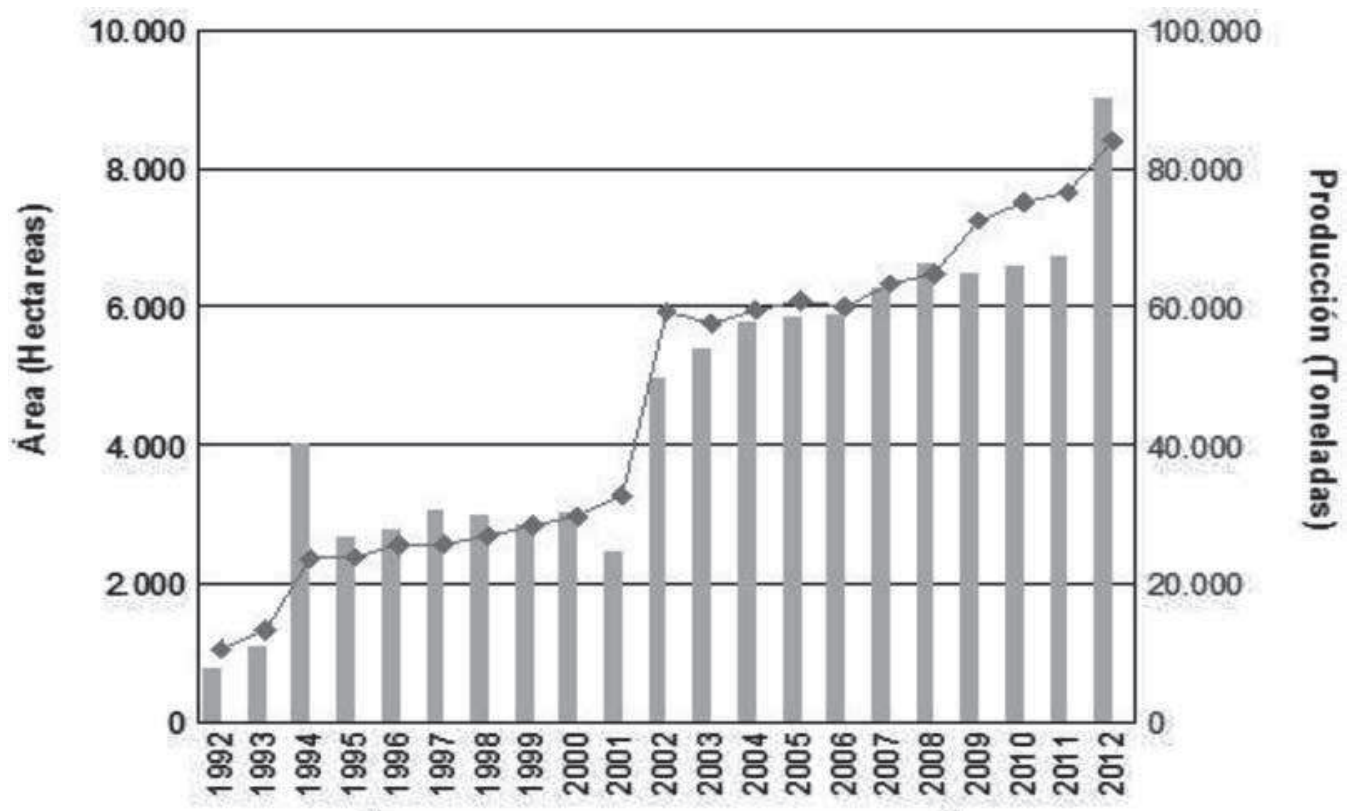

- Área $\quad$ Producción

Fuente: Agronet (2012)

Según Cardozo (2011: 42), la composición de la cadena productiva de mango en la provincia del Tequendama se presenta bajo distintos eslabones, los cuales tienen diversas problemáticas que se exponen a continuación de forma sucinta:

- Eslabón materias primas e insumos: No adopción de prácticas de cultivo y cultivos heredados.

- Eslabón de producción: Proporción de pequeños cultivos, desorden en la variedad de frutas cultivadas, no hay producción integrada, industrial y mercados internacionales, altos costos de producción y almacenamiento.

- Eslabón comercializador: Existencia de intermediarios, Fluctuación de precios, deficiencia en los canales de distribución.

- Eslabón de consumo: Falta de análisis de mercado.

- Componente socio empresarial: No hay proyección ni ejecución e proyectos de apoyo, no existe organización de los productores, abandono por parte del gobierno central, idiosincrasia.

- Componente entorno infraestructura: Necesidades básicas de servicios. 
Sin embargo la cadena productiva de mango presenta también ventajas heredadas, como climas benignos, posición geográfica privilegiada, recursos naturales renovables, mano de obra económica.

La comprensión de los antecedentes de la cadena productiva de mango en la provincia del Tequendama por medio de fuentes primarias y secundarias, permitieron un primer acercamiento a la realidad de la región para este cultivo y comprender las variables cualitativas y cuantitativas de esta.

Posteriormente se realizó la conceptualización y caracterización de la cadena productiva de mango con base en las experiencias de campo y la recolección de información por medio de encuestas y literatura provista por los participantes de la cadena.

\section{ACTUALIDAD DE LA CADENA PRODUCTIVA DE MANGO EN LA PROVINCIA DEL TEQUENDAMA - CUNDINAMARCA}

El primero en plantear el concepto de cadena productiva fue Hirschman (Isaza, 2011:9), esta se define como la relación que existe entre distintos entes (eslabones), los cuales suministran todos sus recurso para intervenir en un proceso productivo; desde la fase de abastecimiento hasta llegar al consumidor final. Durante todo el proceso los eslabones intercambian materiales e información, articulándose y desempeñándose como un sistema.

Castro (2003: 4), expone una articulación teórica de la cadena productiva con cada uno de sus eslabones (Figura 3), el cual presenta un entorno organizacional: donde participan entidades públicas o privadas que la apoyan; e institucional: que la regula normativa y legalmente. Estos entornos transmiten a la cadena flujos de información o servicios de apoyo. Por otro lado los eslabones transfieren materiales o productos, realimentados por una trasferencia de capital.

Figura 3. Estructura de la cadena productiva.

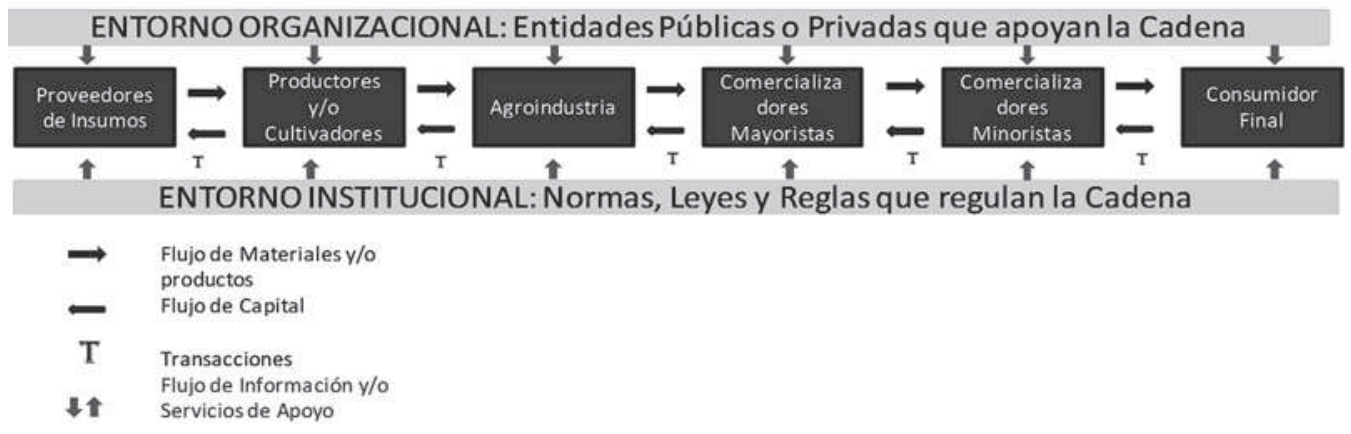

Fuente: Antonio Castro, 2003

La primera meta en el proyecto de investigación era caracterizar la cadena productiva de mango en la provincia del Tequendama, sin embargo las limitaciones de la investigación no permitieron analizar cada uno de los municipios de la 
provincia. Por lo tanto se consideró una muestra por conveniencia en donde se tenía en cuenta los cinco (5) municipios que presentaban las mejores condiciones de producción, productividad y acceso a la información. En estos se realizó el estudio de campo en donde se aplicaron encuestas para conocer las variables en el proceso de abastecimiento, producción y comercialización que permitieron caracterizar la cadena y realizar el modelo de simulación. Los cinco municipios seleccionados fueron: La Mesa, Anapoima, Tocaima, El Colegio y Viotá. En ellos se accedió a información de la siguiente forma:

- Cadena productiva de mango Ministerio de Agricultura y Desarrollo Rural: En la fase inicial del proyecto se tuvo la oportunidad de participar en las reuniones celebradas por dicha estructura, compuesta por todos los involucrados de la cadena productiva a nivel nacional. De ella se extrajo información sobre las necesidades, problemáticas y situación de la cadena productiva en la actualidad.

- Documental: Durante las visitas de campo a los municipios, se tuvo acceso a fuentes de información primarias y secundarias, lo cual permitió conocer la cadena productiva desde otros puntos de vista o investigaciones previas, realimentando el estado del arte que se había realizado con anterioridad.

- Asociaciones: Las asociaciones permitieron llegar a los productores de una forma más organizada. Fueron importante fuente de información durante todo el proceso investigativo.

- Productores: Por medio de ellos se conoció la cadena productiva de mango. Ellos, fuente de todo el conocimiento, proveyeron de forma muy solícita la información que permitió hacer el análisis prospectivo y caracterización de la cadena.

Con base en esta visita de campo se pudo realizar la caracterización de la cadena productiva de mango. En la provincia del Tequendama se puede generalizar un tipo de articulación de los eslabones de cómo se realiza la transferencia de productos entre los distintos partícipes de la cadena.

De los seis eslabones citados por Castro (2003: 4), en la Provincia del Tequendama se articulan cinco (5) de ellos ${ }^{2}$ :

1. Proveedores de insumos/ Proveedores de servicios

2. Productores y/o cultivadores

3. Intermediario/ Distribuidores mayoristas o minoristas

4. Comercializador

5. Consumidor Final / Consumidor Institucional.

2. Se aclara que en muchas ocasiones existe el intermediario comercializador, que se presenta o aparece en las relaciones de negociación de uno o varios eslabones de acuerdo a la dinámica de comercialización que se da entre los mismos y la condiciones del mercado, mientras que los entornos organizacional e institucional permanecen estables. 
En la cadena productiva de mango no se denota una composición agroindustrial del cultivo y en pocas ocasiones se presentan negociaciones con compañías que transforman el producto (Figura 4).

Figura 4. Estructura de la cadena productiva de mango en la provincia del Tequendama

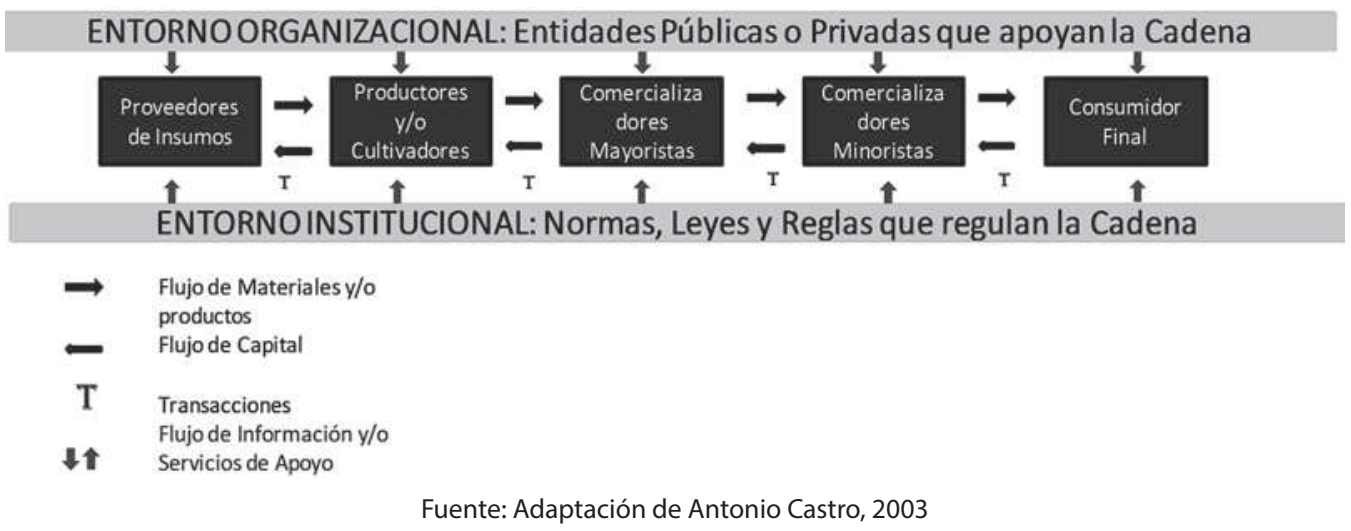

No existe un mercado externo dado que no se presentan las condiciones propicias de calidad, volúmenes de negociación, logística, entre otras variables, lo que imposibilita el ingreso del producto en dicho mercado.

Por ende, en esta cadena productiva se presenta una comercialización y distribución del producto en fresco, con un alcance regional del producto. Lo que indica que por el momento no existe una estructura exportadora de la cadena.

Las condiciones de cada uno de los eslabones de la cadena productiva permanecen constantes, tanto sus virtudes como fortalezas, con respecto a lo afirmado por Cardozo (2011: 42). Pese a que por medio de las estructuras asociativas se han logrado negociaciones con grandes superficies, beneficios en la adquisición de insumos, capacitaciones y consolidación de carga, se puede afirmar que las condiciones de la cadena productiva de mango son constantes, inclusive los precios de compra que paga el intermediario al productor permanecen inmutables, en detrimento del poder adquisitivo de los productores. Adicionalmente se pudo identificar que las condiciones de los productores no son las más favorables y se relacionará el por qué de dicha situación dada cada variable relevante:

Ubicación geográfica: Está directamente relacionada con las condiciones de transporte, debido a que es una constante encontrar un mal estado de las vías terciarias en la provincia. Adicionalmente la distancia puede ser una variable determinante dado los costos de transporte y gasolina, lo cual incrementa los costos de los productores.

Costos de transporte: Esta variable se presenta cuando los productores desean movilizar sus mercancías a la plaza de su conveniencia, y su costo es considerable dado que se tienen en cuenta el costo de gasolina, operario y mantenimiento del 
vehículo, costos que son traducidos al consumidor de este servicio. Sin embargo hay una prelación por vender en finca, por parte del productor.

Precio de insumos al productor: Los costos de insumos son elevados, teniendo en cuenta el costo marginal por unidad producida. Existe una imposibilidad por parte de los productores de acceder a menores precios de insumos debido a que sus terrenos son pequeños o medianos (Entre 1 y 20 fanegas en promedio), lo que genera que no puedan acceder a economías de escala.

Costos de Mano de Obra: Pese a que los costos de mano de obra son económicos, y hay mayor tendencia a contratar jornales que a realizar contratos de trabajo, la oferta de mano de obra es cada vez más escasa en la zona rural, dada la tendencia de las generaciones más jóvenes a migrar a zonas urbanas.

Cantidad Producida: Los niveles de producción no son óptimos, debido a que no existe tecnificación de los cultivos y se puede afirmar que en una gran proporción de las fincas se tienen condiciones de cultivo neolíticas. Esta condición limita las negociaciones con compradores extranjeros.

Plagas y Enfermedades: La mosca de la fruta (Drosophila melanogaster) y la hormiga arriera (Atta spp $\&$ Acromyrmex spp) son plagas que afectan la producción de las fincas. Entre el $10 \%$ y $20 \%$ de la producción pueden llegar a afectar estas plagas en temporada de cosecha. Pese a que distintas entidades han capacitado para combatir estas plagas, los cultivos extensivos generan condiciones favorables para el desarrollo de estas plagas.

Suelo: Cabe anotar que los productores de la provincia, pese a que tienen por actividad principal el cultivo de mango, realizan otro tipo de cultivos como cítricos o plátano. Esta condición y la falta de capacitación en el manejo de los suelos, van en detrimento de la productividad del terreno.

Desperdicio: Adicionalmente a las problemáticas derivadas de las plagas, las enfermedades, las condiciones de salida del producto a las plazas, las condiciones de la demanda y el clima, múltiples factores generan la pérdida de producto con anterioridad a la vendimia.

Precio del Producto: Existe un gran desbalance con respecto a los precios que se le paga al productor, con respecto a los que se le paga al intermediario. Los precios pagados al productor, le permiten pagar los costos de producción y recibir un pequeño margen de ganancia. Infortunadamente el productor debe acceder a los términos de negociación del intermediario, so pena de perder toda la producción accediendo muchas veces a transacciones leoninas. El intermediario por otro lado, compra a un precio bajo e incrementa los precios del producto hasta un $200 \%$. El consumidor final se ve afectado debido a que paga altos precios por el producto en una plaza.

Inversión: La operación en la mayoría de fincas no da margen para realizar un apalancamiento operativo. Por otro lado los créditos bancarios y las tasas de interés generan que los préstamos sean de alto costo para los productores, llegando al punto de declararse insolventes para cancelar sus obligaciones. 
Tamaño del Terreno: Los terrenos tienden a ser pequeños o medianos, lo que impide la adopción de economías de escala. En general se denota un incremento gradual en el precio de la finca raíz en los municipios de la provincia.

Almacenamiento: Por lo general no existe el proceso de almacenamiento por parte del productor. En ocasiones el intermediario utiliza el almacenamiento, pero por lo general llevan directamente los productos a la central de abastos de Bogotá (Corabastos).

Comprendiendo y caracterizando la cadena productiva de mango en la provincia del Tequendama en la actualidad, se pasa a realizar el análisis del futuro probable de la cadena productiva. Para tal labor, se seleccionó la dinámica de sistemas como herramienta que permitiría modelar la cadena productiva de mango bajo distintos escenarios.

\section{FUTURO DE LA CADENA PRODUCTIVA DE MANGO EN LA PROVINCIA DEL TEQUENDAMA - CUNDINAMARCA}

La técnica de dinámica de sistemas fue seleccionada para realizar el análisis prospectivo de la cadena productiva de mango, después de efectuar un proceso de conceptualización en donde se encontró similitudes entre el concepto de cadena productiva y sistema.

La articulación de conceptos inició con la definición del Centro Internacional de Prospectiva (Berger, 1960:1), el cual afirma que la prospectiva es la ciencia que tiene como objeto estudiar las causas técnicas, científicas, económicas y sociales, que aceleran la evolución del mundo moderno y las predicciones que puedan derivarse de sus influencias combinadas. Lo cual comprende el futuro como una realidad múltiple que puede presentarse de distintas formas. La prospectiva hace uso de elementos cualitativos y cuantitativos, siendo muy diversas las metodologías usadas para llegar a predecir los distintos escenarios de lo que se pronostica.

La prospectiva hace uso de tres elementos para comprender y pronosticar: Los expertos, actores y la probabilidad.

Los expertos son las personas que conocen el fenómeno de estudio; sus variables y causalidades, lo cual permite una comprensión de la naturaleza y composición del fenómeno.

Los actores son aquellos que interactúan con el fenómeno de estudio. Por medio de sus actos componen y modifican la realidad, dando molde a una de las posibles realidades ulteriores.

La probabilidad es la herramienta cuantitativa que nos permite tomar decisiones dado un futuro aleatorio, teniendo como base las experiencias pasadas.

Estos tres elementos interactúan y al ser analizados componen el análisis prospectivo, partiendo de la base de los escenarios probables que serán determinados por las opiniones de los expertos y los anhelos de los involucrados.

En segunda instancia se conceptualizó la dinámica de sistemas como una técnica de simulación que busca proyectar y predecir el futuro, teniendo como sustento 
racional la teoría de sistemas. Con respecto a los sistemas Aracil y Gordillo los definen como:

Un objeto formado por un conjunto de partes entre las que se establece alguna forma de relación que las articula en unidad que es precisamente el sistema. Un sistema se nos manifiesta como un aspecto de la realidad dotado de cierta complejidad precisamente por estar formado por partes en interacción. Esta interacción coordina a las partes dotando al conjunto de una entidad propia. Las partes y la interacción entre ellas son los elementos básicos en esta concepción de sistema. Un sistema se percibe como algo que posee una entidad que lo distingue de su entorno, aunque mantiene interacción con él. Esta identidad permanece a lo largo del tiempo y bajo entornos cambiantes (Aracil y Gordillo, 1997:11).

Ambos elementos se vinculan dado que la dinámica de sistemas es una herramienta para predecir y la prospectiva es una metodología que busca generar la comprensión y predicción del futuro por escenarios.

La dinámica de sistemas como herramienta, permite modelar variables cuantitativas que se vinculan para crear el sistema, estas pueden ser modificadas de forma creciente o decreciente lo cual genera los escenarios probables. Por ende la dinámica de sistemas permite realizar un análisis prospectivo del objeto de estudio en coherencia con la metodología de prospectiva, convirtiéndose en un instrumento de toma de decisiones para los involucrados en la cadena productiva.

La fase inicial de construcción del modelo de simulación comprende el desarrollo del diagrama de influencias. Dicho diagrama se desarrolló con base en las experiencias de campo y la recolección de información. Varios modelos de simulación de otras cadenas productivas sirvieron como base para realizar el propio. Entre varios estudios analizados de cadenas productivas, se pueden destacar los realizados por Correa (2012), Modelo de simulación bajo dinámica de sistemas para el cultivo de mango en Anolaima y Girardot; Amézquita (2013), Modelo de simulación de distintas cadenas productivas agroindustriales generando una sola red de costos, producción y utilidad; Huertas (2011), Modelo de la cadena de abastecimiento de granadilla en Cundinamarca; y Martínez (2011), Modelo del eslabón de producción de la cadena productiva de cacao.

A continuación se exponen las variables que interactúan en el diagrama de influencias y su relación de retroalimentación por cada eslabón de la cadena productiva (presentado en el XI Congreso Colombiano de Dinámica de Sistemas y en el XI Congreso Latinoamericano de Dinámica de Sistemas):

a) Proveedores de insumos (Figura 5): Las variables que influencian este eslabón son:

Ubicación geográfica: Esta variable influencia los Costos de Transporte de manera positiva, siendo una variable que no presenta realimentación; a mayor distancia del consumidor, mayores costos de transporte se presentan.

Costos de transporte: Esta variable está compuesta por otras variables que la conforman. Entre ellas encontramos el impuesto al rodamiento, mantenimiento 
del vehículo, peajes (en el caso que se presente), precio de la gasolina (variable no controlable), operario, costos de carga y descarga, entre otras variables que se acumulan como costos del proveedor y que se ven reflejados en el precio al consumidor. Se presenta una relación de influencia positiva con los Precios de Insumos al Proveedor.

Precio de insumos al productor: Es el reflejo de todos los costos de producción, operativos, administrativos, de transporte y se le agrega la utilidad que percibe el proveedor de la cadena. Presenta una realimentación positiva con los costos de transporte y una realimentación negativa con respecto a la cantidad demandada.

Calidad del insumo: La calidad del insumo hace referencia a la eficiencia y eficacia del mismo producto que se vende, a mayor calidad de insumo, mayor es el costo de este, por tal razón influencia positivamente el precio de insumos al productor ${ }^{3}$.

Cantidad Demandada: La cantidad demandada de insumos por el productor está relacionada con el número de productos adquiridos, dada una restricción presupuestal del comprador (en el caso de la cadena, productor y/o cultivador). La cantidad demandada es influenciada por los costos de los insumos de manera negativa al igual que con el precio. Por otro lado realimenta de forma negativa los costos de transporte, dado que a mayores volúmenes de demanda de insumos, los costos de transporte serán menores.

Las anteriores variables se relacionan con el siguiente eslabón de la cadena (Productores y/o Cultivadores), por medio de la variable Costos Insumos/Ingreso Proveedor. Adicionalmente existen variables externas, no controlables, que influyen en este eslabón de la cadena y que serán relacionados con posterioridad.

Figura 5. Diagrama de Influencias eslabón Proveedor de Insumos.

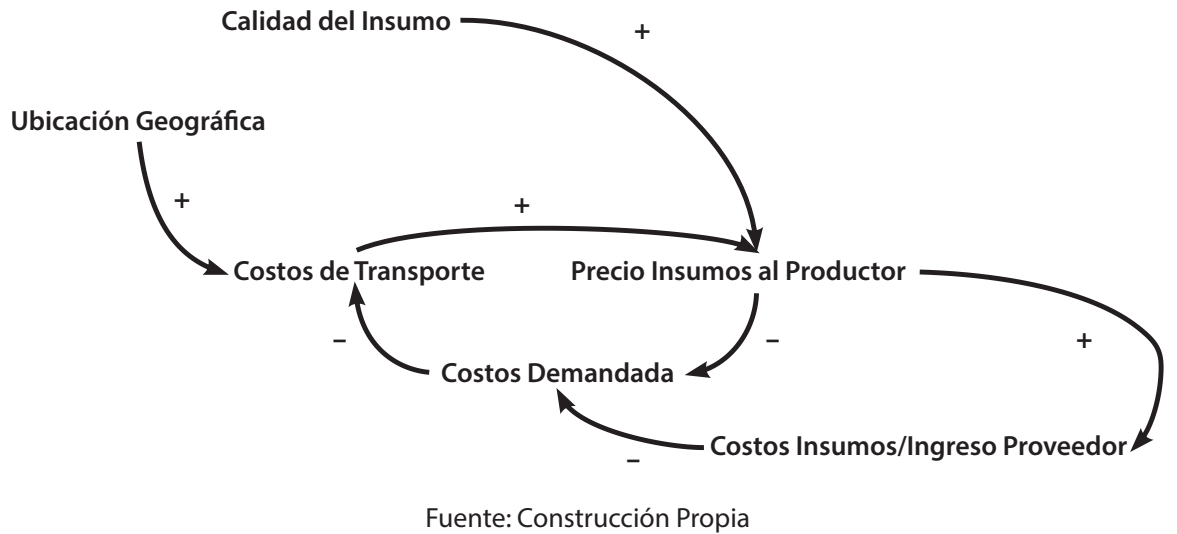

3. Al analizar el diagrama de influencia, se denota una prelación del consumidor a adquirir productos menos costosos, lo cual no indica que exista una demanda superior de productos de menor calidad, sino que se presume que existe una elasticidad precio de la demanda $>1$ para los insumos al productor, dada la relación inversa que guardan entre si el precio y la cantidad. 
b) Productores y/o Cultivadores (Figura 6): Las variables que influencian este eslabón son:

Costos Insumos/Ingreso Proveedor: Esta variable está compuesta por diversos rubros que se han identificado como: Semillas/Plántulas, Fertilizantes, Control Sanitario (Herbicidas, Insecticidas, Fungicidas, Control Biológico), Agua, Empaque y Otros Insumos. Influencia positivamente los Costos Totales y el Suelo. Es influenciado negativamente por los Desperdicios y los Costos Totales. Así mismo, es influenciado positivamente por la Disponibilidad de Tierra y la Inflación.

Costos de Mano de Obra: Esta variable está compuesta por diversos rubros divididos en tres fases productivas que son: Preparación (Arada, Rastrillada, Nivelada, Correctivos y Riego), Cultivo (Siembra, Resiembra, Raleo, Apoque, Control de Maleza, Aplicación Pre-Emergentes, Aplicación Pos-Emergentes, Aplicación Fertilizantes, Control de Plagas y Control de Enfermedades) y Cosecha (Recolección, Empaque, Clasificación, Zorreo y Transporte). Influencia positivamente los Costos Totales, por otro lado es influenciado positivamente por la Disponibilidad de Tierra y la Inflación y negativamente por los Costos Totales.

Otros Costos: Esta variable está compuesta por diferentes rubros como Administración, Asistencia Técnica, Arrendamiento e Intereses. Influencia positivamente los Costos Totales y es influenciado positivamente por la Inflación, las Tasas de Interés y la Disponibilidad de Tierra, es influenciado negativamente por los Costos Totales.

Costos Totales: Influencia positivamente la Cantidad Producida, y negativamente los Costos Insumos/Ingreso Proveedor, Costos de Mano de Obra, Costos Totales, Plagas y Enfermedades. Es influenciado positivamente por Otros Costos, Costos de Mano de Obra, Costos Insumos/Ingreso Proveedor e Inversión, y es influenciado negativamente por la Cantidad Producida.

Cantidad Producida: Esta variable influencia positivamente los Desperdicios e influencia negativamente los Costos Totales. Es influenciado positivamente por el Suelo, Clima y Costos Totales, negativamente por Plagas y Enfermedades.

Plagas y Enfermedades: Esta variable es influenciada negativamente por Costos Totales, e influencia negativamente la Cantidad Producida.

Suelo $^{4}$ : Influencia positivamente la Cantidad Producida y es influenciado positivamente por Costos Insumos/Ingreso Proveedor.

Desperdicio ${ }^{5}$ : Esta variable es influenciada positivamente por la Cantidad Producida y positivamente por la Cantidad No Demandada de Producto. Influencia positivamente la Cantidad Disponible para la Venta y Costos Insumos/Ingreso Proveedor.

Cantidad Disponible para la Venta: Influencia negativamente a la Cantidad Demandada de Producto y es influenciado negativamente por los Desperdicios.

4. Hace referencia a las condiciones del suelo como el $\mathrm{pH}$, salinidad, entre otras variables que influyen en la calidad del cultivo.

5. Desperdicios hace referencia al producto que se pierde en el proceso productivo o el fruto que no es apto para el consumo y es reutilizado como abono orgánico. 
Cantidad Demandada de Producto: Influencia negativamente el Precio del Producto y los Desperdicios. Es influenciado negativamente por la Cantidad Disponible para la Venta, Ingreso Productor/Costo Comercializador y por el Contrabando.

Cantidad No Demandada del Producto: Guarda una relación inversa con la Cantidad Demandada del Producto. Influencia positivamente los Desperdicios de la operación.

Precio del Producto: Influencia positivamente el Ingreso Productor/Costo Comercializador y es influenciado negativamente por la Cantidad Demandada del Producto.

Ingreso Productor/Costo Comercializador: Influencia positivamente la Utilidad del Productor y negativamente la Cantidad Demandada del Producto. Es influenciado positivamente por el Precio del Producto.

Utilidad Productor: Influencia Positivamente la Inversión. Es influenciado positivamente por el Ingreso Productor/Costo Comercializador y negativamente por los Impuestos y el Orden Público.

$\underline{\text { Inversión }}^{6}$ : Influencia positivamente los Costos Totales y la Disponibilidad de Tierra. Es influenciado positivamente por la Utilidad del Productor y negativamente por las Tasas de Interés.

Tamaño del Terreno: Influencia positivamente los Costos Insumos/Ingreso Proveedor, Costos de Mano de Obra y Otros Costos. Es influenciado positivamente por la Inversión.

Adicionalmente existen variables que influyen en el rendimiento y comportamiento del proceso productivo como es el factor Técnico/Tecnológico (Figura 7) y Factores Logísticos Adecuados (Figura 8). La primera variable influye negativamente en los Costos de Mano de Obra, Costos Insumos/Ingreso Proveedor y Otros Costos (directamente en Costos de Asistencia Técnica/e Intereses que deben pagarse. Es influenciado positivamente por Otros Costos (Intereses/Crédito) y por la Inversión. La segunda variable influencia negativamente los Costos de Mano de Obra y Otros Costos. Es influenciado positivamente por Otros Costos (de Administración y Asistencia Técnica).

Existen También variables no controlables que influyen en el comportamiento de este eslabón. En la cadena se presenta el fenómeno de Inflación, que influencia todos los costos de manera positiva (Costos de Mano de Obra, Costos Insumos/Ingreso Proveedor y Otros Costos). El Clima que influencia positivamente la Cantidad Producida. El contrabando que influencia negativamente la Cantidad Demandada de Producto. Los impuestos que influyen negativamente en la Utilidad del Productor. Condiciones de Orden Público que influyen negativamente en la Utilidad del

6. Hace referencia al apalancamiento operativo de la empresa. Guarda una relación inversa con las tasas de interés debido a que en la medida que existan tasas más altas en el mercado, existe un incentivo mayor a invertir en el mercado financiero. 
Productor. Y las Tasas de Interés que guardan una relación inversa con la Inversión ${ }^{7}$ e influencian positivamente Otros Costos (Intereses).

Figura 6. Diagrama de Influencias eslabón Productor.

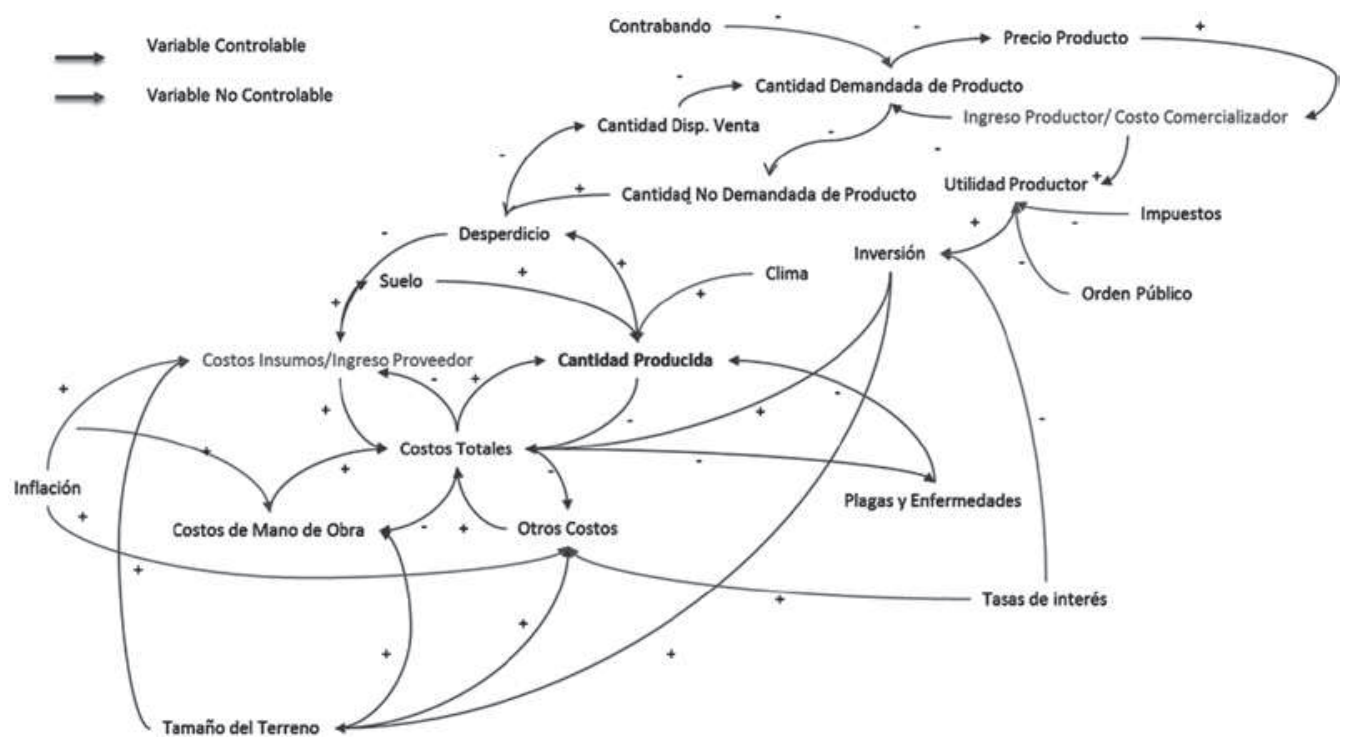

Fuente: Construcción Propia

Figura 7. Diagrama de Influencias Factor Técnico/ Tecnológico.

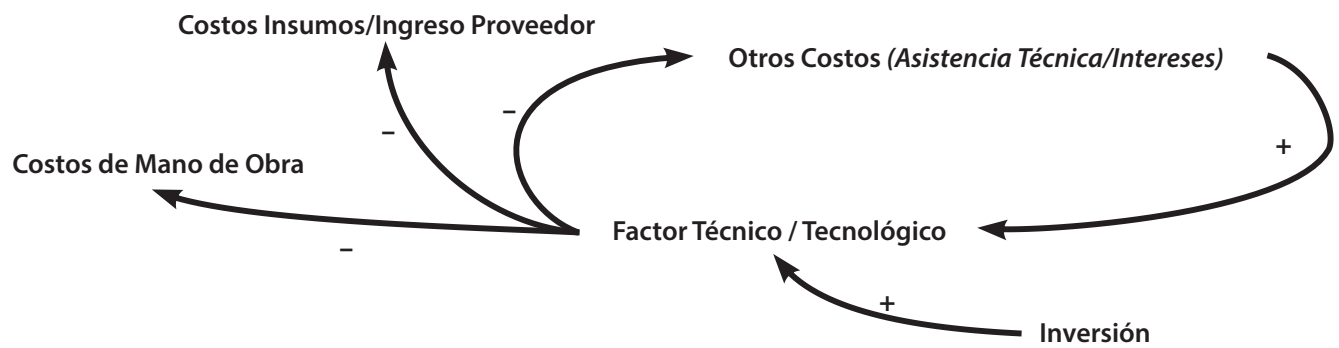

Fuente: Construcción Propia

7. Cuando se presentan mayores tasas de interés en el mercado, existirá una propensión menor a generar un apalancamiento financiero en la cadena y se estimula la inversión en el mercado financiero. 
Figura 8. Diagrama de Influencias Factor Logístico Adecuado

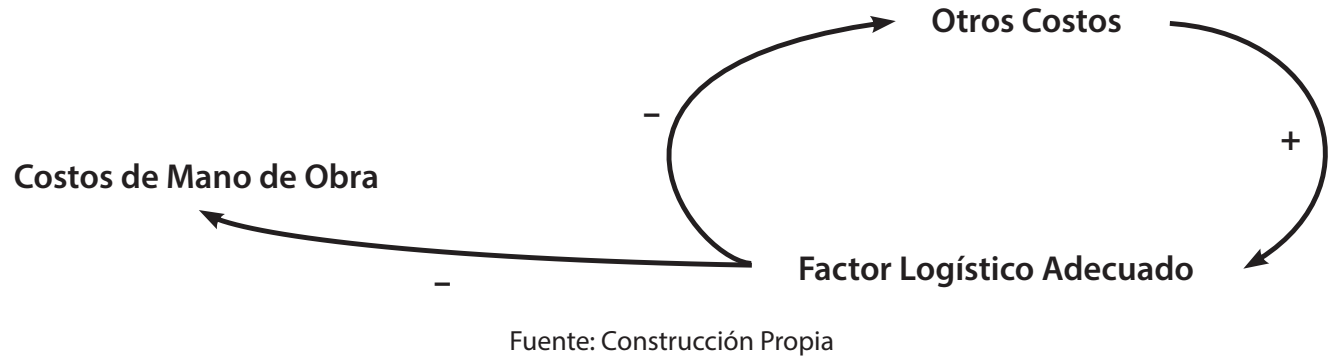

c) Comercializador Mayorista/Minorista (Figura 9): Estos eslabones pueden simplificarse en un diagrama de influencias debido a que los procesos implicados son similares para el Comercializador Mayorista y Minorista, por lo cual solo debería replicarse. En este/os eslabón/es, se pueden encontrar variables controlables y no controlables. En algunos pasos de la comercialización se omiten unos procesos, pero por lo general siempre están involucradas las siguientes variables:

Ingreso Productor/Costo Comercializador: Esta variable influencia positivamente los Costos Totales y es realimentado negativamente por los Costos Totales.

Costo de Mano de Obra: Influencia positivamente los Costos Totales y es realimentado negativamente por esta misma variable.

Ubicación Geográfica: Esta variable influencia los Costos de Transporte de manera positiva, siendo una variable que no presenta realimentación; a mayor distancia del consumidor, mayores costos de transporte se presentan.

Costos de Transporte: Influencia positivamente los Costos Totales y es realimentado negativamente por esta misma variable. Es influenciado positivamente por los Impuestos, los Costos de la Gasolina y los Costos de Peajes. Adicionalmente es influenciado negativamente por la Infraestructura Vial.

Costos de Almacenamiento: Influencia positivamente los Costos Totales y es influenciado positivamente por la Cantidad Demandada.

Costos Totales: Influencia negativamente las variables Ingreso Productor/Costo Comercializador, Costo de Mano de Obra, Costos de Transporte y Cantidad Demandada. Es influenciado positivamente por Ingreso Productor/Costo Comercializador, Costo de Mano de Obra, Costo de Transporte, Costos de Almacenamiento e Inversión, es influenciado negativamente por la Cantidad Demandada.

Cantidad Demandada: Influencia positivamente el Costo de Almacenamiento y negativamente los Costos Totales y el Precio de Venta Consumidor Final. Es influenciado negativamente por los Costos Totales, Ingreso Comercializador/Costo Consumidor y Contrabando. 
Precio de Venta al Consumidor Final: Influencia positivamente el Ingreso Comercializador/ Costo Consumidor y es influenciado negativamente por la Cantidad Demandada.

Ingreso Comercializador/Costo Consumidor: Influencia positivamente la Utilidad de Comercializador y negativamente la Cantidad Demandada. Es influenciado positivamente por el Precio de Venta al Consumidor Final.

Utilidad del Comercializador: Influencia positivamente la Inversión. Es influenciado positivamente por Ingreso Comercializador/Costo Consumidor y negativamente por el Orden Público.

Inversión: Influencia positivamente los Costos Totales. Es influenciado positivamente por la Utilidad del Comercializador y negativamente por las Tasas de Interés.

Entre las variables no influenciables que afectan el eslabón Comercializador Mayorista/Minorista se encuentran la Infraestructura Vial que influye negativamente en los Costos de Transporte, por el contrario influyen positivamente los Impuestos, Costos de Gasolina y Costo Peajes en esta misma variable. El Contrabando influye negativamente en la Cantidad Demandada. El Orden Público influye negativamente en la Utilidad del Comercializador. Las Tasas de Interés influyen negativamente en la Inversión.

\section{Diagrama de Influencias eslabón Comercializador Mayorista/Minorista}

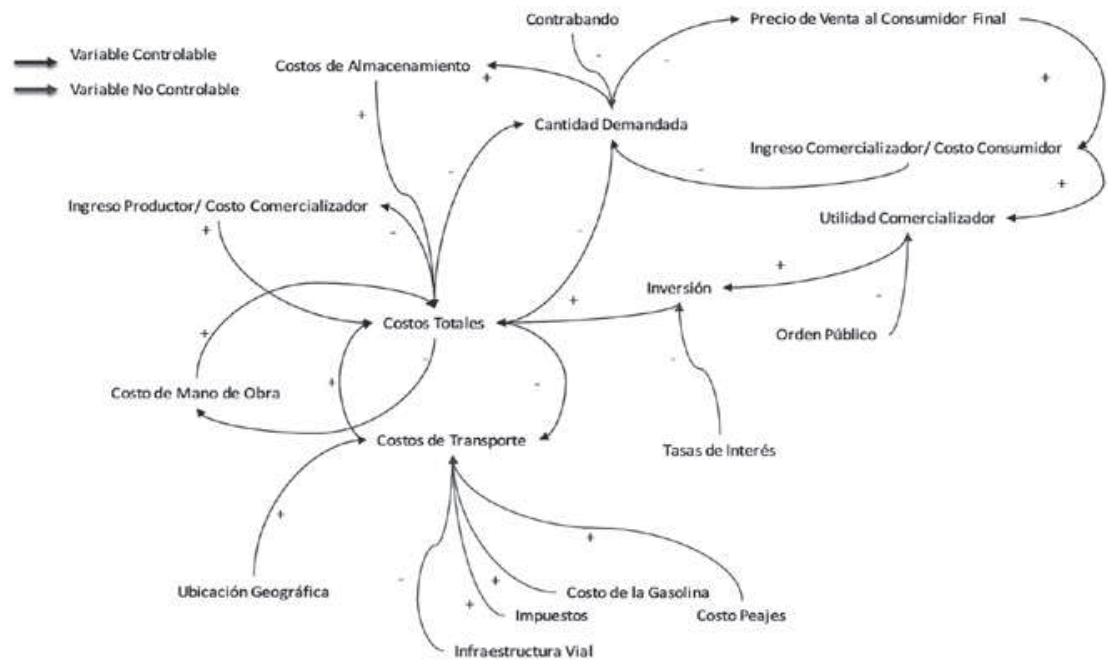

Figura Fuente: Construcción Propia

d) Consumidor Final y/o Institucional: Las variables que influyen en este eslabón no serán expuestas como diagrama causal, debido a que el alcance del estudio analiza hasta el eslabón comercializador. El modelo puede ser modificado en etapas posteriores, para ver el comportamiento del consumidor con respecto a variaciones del precio, mas hasta el eslabón comercializador se realiza el análisis que contribuya a mejorar las condiciones de los productores de la región. 
Después del desarrollo del diagrama de influencias, se realiza la simulación por medio de dinámica de sistemas la cual contiene las variables anteriormente mencionadas.

Se parte de un escenario base ${ }^{8}$ que contiene los valores actuales del proceso de abastecimiento, producción y comercialización en la cadena productiva de la provincia del Tequendama y que fue explicado en el diagrama de influencia.

El análisis se realizó examinando las variables de estado o acumulativas que tienen gran relevancia dada su importancia en el esquema financiero de los productores, estos son los costos y la utilidad. Al dar valores numéricos a las distintas variables expuestas en el diagrama de influencias se puede verificar el comportamiento de estas dos variables, bajo el escenario base y se exponen en las siguientes gráficas (Figuras 10, 11, 12, 13, 14):

Figura 10. Proyección Otros Costos Escenario Base

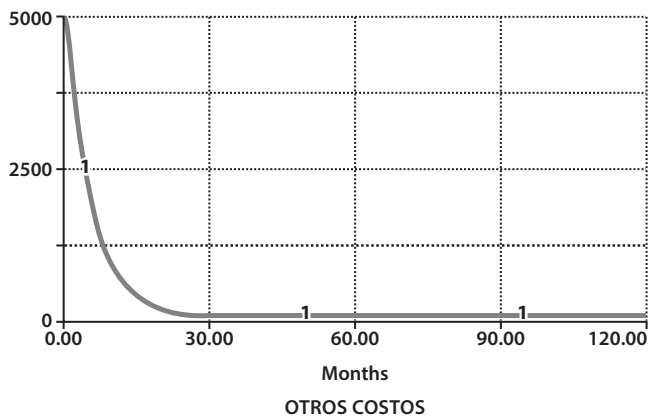

Fuente: Construcción Propia

Figura 12. Proyección Costos Mano de Obra. Escenario Base

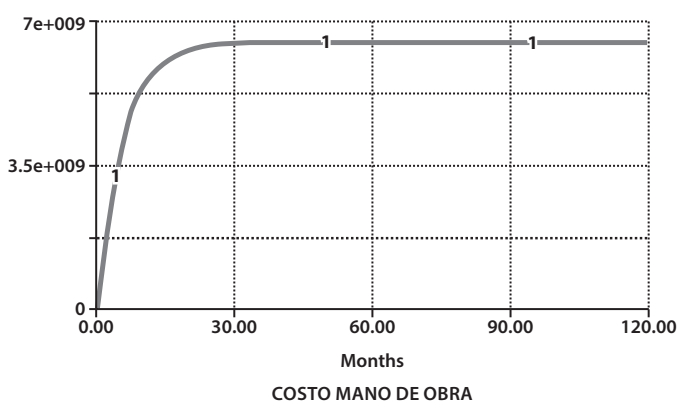

Fuente: Construcción Propia
Figura 11. Proyección Otros Insumos Escenario Base

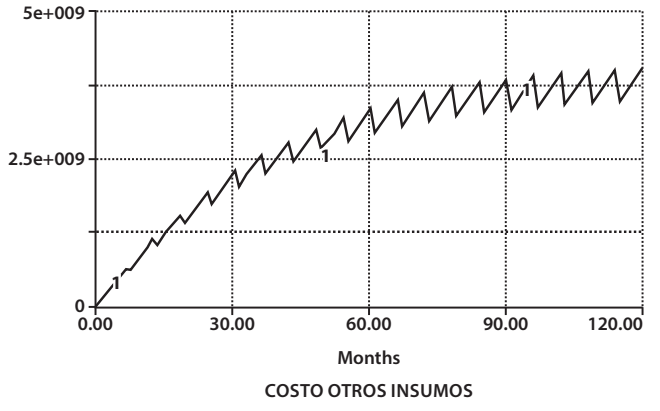

Fuente: Construcción Propia

Figura 13. Proyección Utilidad Escenario Base

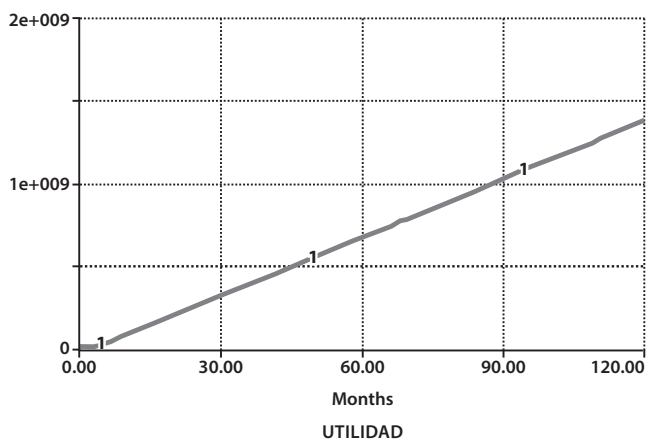

Fuente: Construcción Propia

8. Escenario base sin valores en la variable contrabando, debido a que no se encontraron fuentes primarias ni secundarias que permitieran tener un estimado de este fenómeno. 


\section{Figura 14. Proyección Utilidad Neta Escenario Base.}

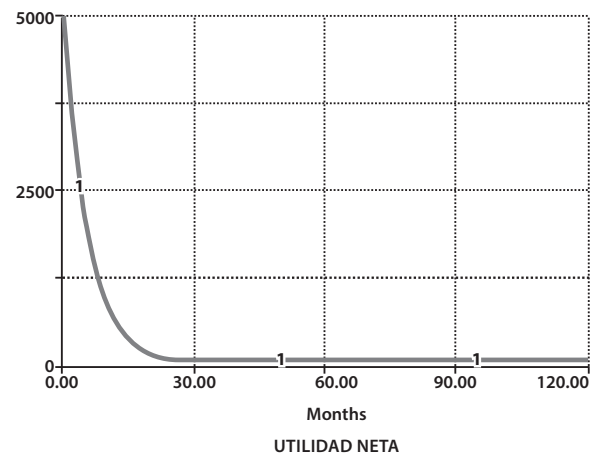

Fuente: Construcción Propia

Dadas las condiciones actuales de la cadena productiva, existe un incremento de los costos (exceptuando la variable otros costos, que no se presentan en la estructura actual de la cadena) ${ }^{9} \mathrm{y}$ un decrecimiento de la utilidad neta a lo largo del tiempo, situación que es afín dado el incremento generalizado de los precios y acorde también a las condiciones de ingreso de los productores en la actualidad. Esto demuestra que el mercado nacional, que es el territorio donde los productores de la provincia comercializan sus productos, no es un escenario óptimo para hacer negocio, de continuar las condiciones actuales de la cadena productiva.

Dado lo anterior, se procede a realizar modificaciones en los valores del modelo para identificar comportamientos y tendencias, que permitan mejorar la utilidad neta de los productores, y por ende se propusieron tres escenarios:

Inicialmente se redujeron los costos de la cadena como medida para incrementar la utilidad neta, presentándose el siguiente comportamiento (Figuras 15 y 16):

Figura 15. Proyección Utilidad Reducción de Costos

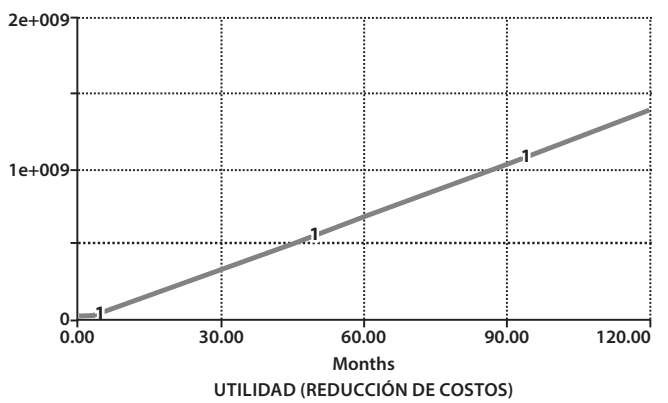

Fuente: Construcción Propia
Figura 16. Proyección Utilidad Neta Reducción de Costos

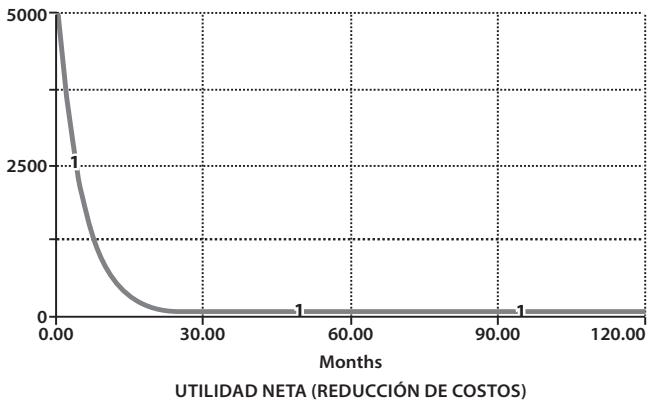

Fuente: Construcción Propia

9. No existen costos de Arrendamientos, Administración y Asistencia Técnica, y no es la generalidad que los productores estén involucrados en un crédito. 
Pese a que se generó una reducción de costos en el modelo, la utilidad neta sigue siendo decreciente a lo largo del tiempo, lo que indica que la solución a las problemáticas de la cadena productiva no provienen de la reducción de costos. Pese a que uno de los factores competitivos de toda actividad económica es la reducción de costos, en la cadena productiva de mango no es una solución por si sola para lograr un incremento en la utilidad neta de los productores.

Con posterioridad se volvió al escenario base y se incrementó el precio como segundo factor competitivo. Este incremento del precio de venta del productor era el que permitiría validar o falsear si el mercado externo era la solución para incrementar los ingresos de los productores. Los resultados fueron los siguientes (Figuras 17 y 18):

Figura 17. Proyección Utilidad Incremento de Precio

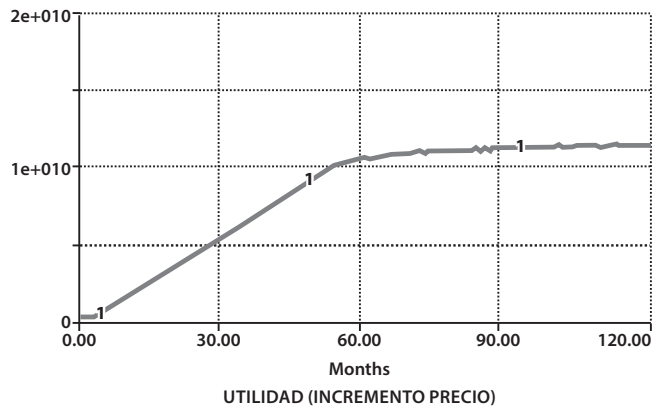

Fuente: Construcción Propia
Figura 18. Proyección Utilidad Neta Incremento de Precio

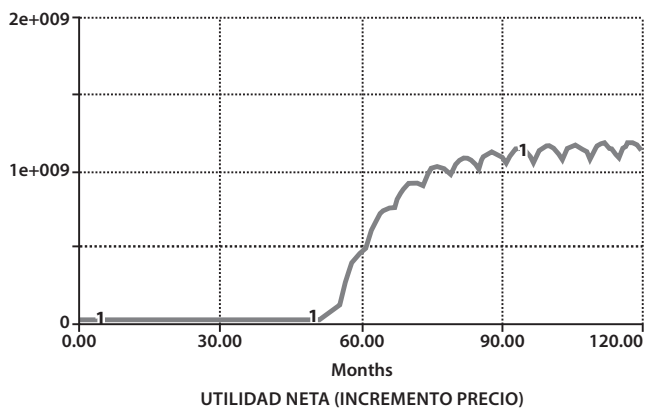

Fuente: Construcción Propia

La variación del precio en el modelo permitió identificar un incremento en la Utilidad y en la Utilidad Neta, por ende uno de los escenarios prospectivos que puede generar mejores condiciones para los productores, es donde se encuentre un mejor precio de venta. Por lo general dicho mercado es externo o uno de calidad en Colombia.

Finalmente, el tercer escenario que se simula con respecto al escenario base, es una disminución en el costo e incremento moderado del precio de venta, lo cual dio como resultado el siguiente escenario (Figuras 19 y 20):

Pese a que la utilidad neta presentó un crecimiento con retraso, se evidencia que este escenario prospectivo presenta incrementos en la utilidad y en la utilidad neta. Por lo tanto un escenario prospectivo donde se disminuyan los costos y se incremente el precio de venta del producto es viable. Este escenario se puede presentar cuando el productor llega directamente al consumidor final, o vende su producto. 

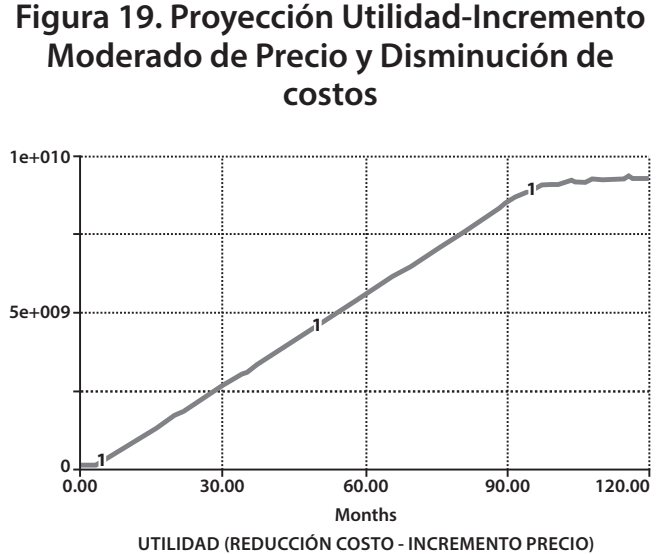

Fuente: Construcción Propia
Figura 20. Proyección Utilidad Neta Incremento Moderado de Precios y Disminución de costos

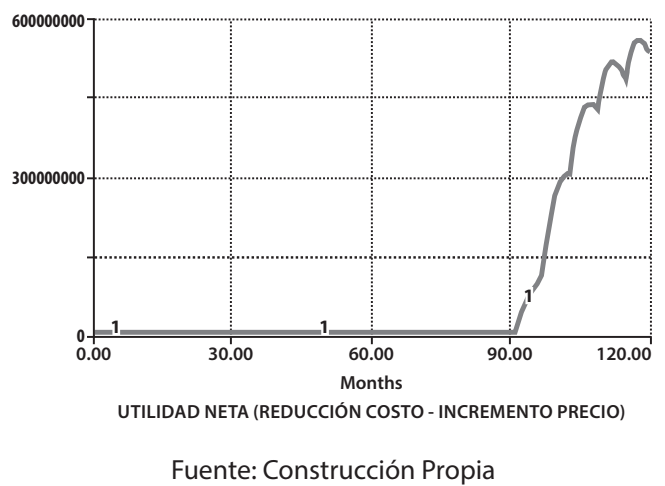

\section{CONCLUSIONES Y RECOMENDACIONES}

El escenario base muestra el comportamiento actual de la cadena productiva de mango el cual tiene un alcance departamental en la distribución del producto. Este escenario no es benigno para los productores, debido a que a lo largo del tiempo pierden poder adquisitivo dado que los precios de negociación del mango han permanecido constantes desde el año 2011.

$\mathrm{Al}$ reducir los costos de la cadena productiva, es posible incrementar los niveles de utilidad de los productores, mas esta política debe ir de la mano con otra que permita proyectar un incremento de la utilidad neta. La reducción de costos pese a que es benéfica, no es una política sostenible por si sola. Por otro lado el incremento del precio si resulta ser una política sostenible, para llegar a ese precio unitario los productores deben realizar esfuerzos por llegar al mercado externo.

Un escenario mixto entre el incremento moderado de precios y la disminución de costos, permitiría a los productores, alcanzar el mercado departamental sin la necesidad de llevar toda su producción al mercado externo. Dicho proceso se logra eliminando intermediarios de la cadena y buscando los canales de distribución para llegar al consumidor final directamente.

Dadas estas condiciones se concluye que el mercado prospectivo que genera beneficio a los productores de la cadena productiva de mango en la Provincia del Tequendama - Cundinamarca puede ser el mercado nacional o internacional, el primero si se logran optimizar los procesos de producción, la reducción de costos y siempre accediendo a un mercado que ofrezca un mejor precio de venta por los productos. Y el internacional es óptimo dados los niveles de precio que se paga por el producto, sin embargo hay que tener en cuenta los procesos de calidad y los requisitos exportadores. 
Las recomendaciones que se pueden proponer, dados los resultados de la simulación y las condiciones actuales de los productores son:

Reducción de Costos: Debido a que el tamaño de terrenos de los productores no permite adoptar economías de escala, se recomienda fortalecer los esquemas asociativos y para generar compras grupales de insumos, lo cual permite reducir el costo marginal de cada producto.

Incremento en el precio: Se debe buscar compradores que ofrezcan un mayor precio por el producto. En Colombia dicho mercado se encuentra eliminando intermediarios en la cadena hasta llegar al consumidor final, dicho incremento será mayor si se alcanza un mercado donde se demande calidad del producto. El mercado externo ofrece mejores precios por el producto, sobre todo Estados Unidos y la Unión Europea, sin embargo el acceso a estos mercados requiere una mejora en la calidad y en los procesos.

El modelo de simulación se presenta a la comunidad académica como herramienta para desarrollar diversos escenarios futuros en la cadena productiva de mango. La fase posterior del proyecto, es validar que el modelo sea coherente con la realidad, recibiendo todas las retroalimentaciones de la comunidad académica.

\section{REFERENCIAS}

AGRONET (2012). Exportaciones del Sector Agropecuario por Sector Agrícola. En: agronet.gov. co [En línea]. Disponible en: http://www.agronet.gov.co/agronetweb1/Estad\%C3\%ADsticas/ ReportesEstad\%C3\%ADsticos.aspx (Consultado May. 14-12).

AGRONET (2012). Producción nacional por producto. En: agronet.gov.co. [En línea]. Disponible en: http:// www.agronet.gov.co/agronetweb1/Estad\%C3\%ADsticas/ReportesEstad\%C3\%ADsticos.aspx (Consultado May. 1-13).

AMÉZQUITA, Julio; CHAMORRO, Karen (2013). Dinámica de sistemas aplicado en el análisis de cadenas productivas agroindustriales en el Departamento de Bolívar. En: icesi.edu.co. p. 11 [En línea]. Disponible en: http://www.icesi.edu.co/revistas/index.php/sistemas_telematica/article/view/1500 (Consultado Jul. 1-13).

ARACIL, Javier; GORDILLO, Francisco (1997). Dinámica de sistemas. En: Cornell University. p. 139. [En línea]. Disponible en: http://tiesmexico.cals.cornell.edu/courses/shortcourse5/minisite/pdf/Literatura/ Aracil\%20Gordillo\%20DS.pdf_(Consultado Jul. 1-13).

ASOHOFRUCOL (2005). La cadena de los frutales de exportación en Colombia. En: asohofrucol.com.co. [En línea].Disponible en: http://www.asohofrucol.com.co/archivos/Cadenas/caracterizacion_frutales_exporta_2005.pdf_(Consultado May. 1-12). 
BERGER. Gaston; OTROS (1960). Prospective. Presses Universitaires de France. París. Septiembre, primera edición. $114 \mathrm{p}$.

CARDOZO, Julián; OTROS (2011). Propuesta para el desarrollo de un Cluster frutícola en el Departamento de Cundinamarca.. En: urosario.edu.co, p. 94 [En línea]. Disponible en: http://repository.urosario.edu.co/ bitstream/10336/2279/1/1020734967-2011.pdf (Consultado Ago. 3-12).

CASTRO, Antonio (2003). Metodología para prospección de la cadena productiva de pesca. En: United Nations Industrial Development Organization. p. 25 [En línea]. Disponible en: http://www.unido.org/ fileadmin/import/23304_Metodologaparaprospeccindelacadenaproductivadepesca.pdf_(Consultado Ago. 1-12).

CORREA, Laura (2012). Modelo de simulación bajo sistemas de producción y mercadeo para el cultivo de mango en Anolaima y Girardot. En: unipiloto.edu.co. p. 12 [En línea]. Disponible en: http://polux.unipiloto. edu.co:8080/00000594.pdf_(Consultado Jul. 1-13).

DEPARTAMENTO NACIONAL DE PLANEACIÓN (2010). Plan Nacional de Desarrollo. En: dnp.gov.co. Tomo I [En línea]. Disponible en: https://www.dnp.gov.co/PND/PND20102014.aspx (Consultado Ago. 7-12).

FAOSTAT (2013). Countries by Commodity. En: faostat.fao.org [En línea]. Disponible en: http://faostat.fao. org/site/339/default.aspx_(Consultado Jul. 9-12).

GUADARRAMA, Pablo (2009). Dirección y asesoría de la investigación científica. Editorial Magisterio. Bogotá D.C., primera edición. 238 p.

HUERTAS, Isaac; OTROS (2011). Modelo de dinámica de sistemas para la cadena de abastecimiento de la granadilla en Cundinamarca, Colombia. En: urosario.edu.co. p. 8 [En línea]. Disponible en: http://www. urosario.edu.co/Administracion/documentos/9-Dinamicas/020_1701714020/_(Consultado Jul. 1-13).

ISAZA, Guillermo (2011). Cadenas productivas. Enfoques y precisiones conceptuales. En: Revista Sotaviento. p. 25 [En línea]. Disponible en: http://190.7.110.123/pdf/5_revistaSotavento/pdfSotavento/Sotavento\%20 11/Jairolsaza.pdf.(Consultado Sep. 1-12).

MARTÍNEZ, Natalia. ANDRADE, Hugo (2011). Propuesta de un modelo con dinámica de sistemas como herramienta en el aprendizaje del eslabón de producción de la cadena productiva de cacao. En: urosario. edu.co. p. 8. [En línea]. Disponible en: http://www.urosario.edu.co/urosario_files/42/42de7316-fa30-4632921e-6b4308c97631.pdf (Consultado Jul. 1-13).

MINISTERIO DE AGRICULTURA Y DESARROLLO RURAL (2003). Ley 811 de 2003. En: minagricultura.gov. co. p. 15 [En línea]. Disponible en: https://www.minagricultura.gov.co/Normatividad/Leyes/ley_811_03. pdf (Consultado Jul. 9-12).

UNIVERSIDAD DEL ROSARIO (2011). Planes de Competitividad en cuatro (4) Provincias de Cundinamarca: Almeidas, Alto Magdalena, Tequendama y Sabana Occidente. En: urosario.edu.co [En línea]. Disponible en: http://www.urosario.edu.co/urosario_files/59/596882be-3ae9-4ea2-a9b5-95513fd53cfc.pdf_(Consultado Ago. 3-12). 